Esta obra está sob o direito de Licença Creative Commons Atribuição 4.0 Internacional.

\title{
PARCERIA DE SUCESSO: FAMILIA E ESCOLA JUNTOS POR UMA EDUCAÇÃO INCLUSIVA SIGNIFICATIVA E DE QUALIDADE.
}

\author{
Cassiane Alves Santos Bispo ${ }^{1}$ \\ Ivaldo Sales Nascimento Júnior ${ }^{2}$ \\ Bernard Pereira Almeida ${ }^{3}$ \\ Joselito Araújo Silva ${ }^{4}$ \\ Adriana Cavalcante da Silva Lessa ${ }^{5}$ \\ Wesley dos Santos Lima
}

\section{RESUMO}

A família é o primeiro grupo social ao qual pertencemos sendo assim, a mesma se faz indispensável para o desenvolvimento da educação inclusiva de qualidade. À vista disto se faz necessário que pais e professores trabalhem juntos a fim de que ocorra uma aprendizagem significativa onde os educandos sintam-se amados e inseridos de fato no contexto escolar. Desta forma, o objetivo deste trabalho é elucidar a necessidade da parceria família-escola para que assim a educação inclusiva venha a ser desenvolvida de forma satisfatória. Entretanto, para que isso aconteça é preciso desenvolver um trabalho baseado no respeito mutuo onde todos os envolvidos no processo de ensino-aprendizagem reconheçam a importância de sua participação ativa contribuindo assim para o desenvolvimento de nossas crianças e adolescentes.

PALAVRAS CHAVES: Família. Escola. Educação Inclusiva. Parceria.

\footnotetext{
1 profcassiane2014@gmail.com

2 ivaldosalesjunior@bol.com.br

3 bernardadv@hotmail.com

4 joselitoaraujo947@gmail.com

5 adrianacavalcante32@hotmail.com

${ }^{6}$ wesleyecristo@gmail.com
} 


\section{INTRODUÇÃO}

$\mathrm{Na}$ atualidade estamos vivenciando um momento singular na educação, pois, tornasse cada vez mais frequente a inserção de crianças e adolescentes com Necessidades Educacionais Especiais (NEE) nas escolas regulares. Diante disto, não podemos deixar despercebido à importância da parceria família-escola para que de fato haja uma educação inclusiva significativa e de qualidade. Estudos indicam que quanto mais a família participa da vida escolar das crianças e adolescentes mais significativa tornasse a aprendizagem já que os mesmos se sentam amados e protegidos. Porém, a escola deve mostrar a essas famílias a importância de as mesmas estarem envolvidas no âmbito escolar já que mesmo no momento atual com tantas mudanças ocorridas na área educacional ainda existem pais e responsáveis que desconhecem a relevância que os mesmos podem exercer na aprendizagem e no processo de integração dos educandos. Toda via, se faz indispensável que além da família a escola disponha de profissionais especializados que possam contribuir e auxiliar os professores no processo de inclusão, pois, se faz necessário que o espaço escolar se torne cada vez mais atrativo e aberto a comunidade na qual encontrasse inserida. Sabemos que a ideia de inclusão há muito tempo encontrasse presente na Legislação Brasileira, porém as crianças com Necessidades Educacionais Especiais (NEE) eram atendidas em internatos ou nas escolas especiais seguindo o modelo europeu, fazendo com que essas crianças fossem separadas das demais, ou seja, eram isoladas e privadas do convívio com outras crianças as quais não apresentavam

Necessidades

Educacionais Especiais fazendo com que o preconceito tornasse cada vez mais acentuado, sendo assim, se faz necessário que a inclusão aconteça de fato, ou seja, é preciso que as crianças e adolescentes com NEE frequente a escola regular e tenham o acompanhamento adequado para $\mathrm{O}$ desenvolvimento intelectual e social. À vista disto, é preciso que estejamos atentos às necessidades de mudanças educacionais onde se faz necessário a integração da família firmando a importância da mesma no âmbito escolar. Ou seja, devemos romper as barreiras buscando nos apropriar de práticas mais inclusivas onde todos que estejam inseridos nesse processo sintamse valorizados reconhecendo assim a importância de sua contribuição para que tenhamos uma Educação Inclusão significativa e de qualidade. 


\section{METODOLOGIA}

O presente estudo se desenvolveu por meio de uma revisão de literatura de natureza qualitativa. Para a produção desta pesquisa inicialmente foi estabelecida identificação do tema: PARCERIA FAMILIA-ESCOLA PARA UMA EDUCACAO INCLUSIVA SIGNIFICATIVA E DE QUALIDADE. Para as fontes adquiridas foram utilizadas bases de dados online por meio dos descritores utilizados na pesquisa. A fim de determinar as informações relevantes que seriam extraídas na revisão.2.

É perceptível que a cada dia a quantidade de educandos com Necessidades Especiais Educacionais (NEE) na rede regular de ensino tem seu número aumentado a cada ano. Esse fato não está acontecendo aleatoriamente, isso ocorre que temos leis com a Constituição Brasileira de 1988, a Lei de Diretrizes e Bases da Educação Nacional (LDB), o Estatuto da Criança e do Adolescente (ECA), a Declaração de Salamanca, a Convenção de Guatemala, entre outras leis que asseguram que todas as crianças e adolescentes tem direito garantido de frequentar o ensino regular.

Como também, deixa claro que jovens com NEE devem ser atendidos por profissionais especializados preferencialmente dentro da própria escola que o mesmo venha a frequentar.

Sendo assim conforme o Ministério da Educação,

As definições do público alvo devem ser contextualizadas e não se esgotam na mera categorização e especificações atribuídas a um quadro de deficiência, transtornos, distúrbios e aptidões. Considera-se que as pessoas se modificam continuamente transformando $o$ contexto no qual se inserem. Esse dinamismo exige uma atuação pedagógica voltada para alterar a situação de exclusão, enfatizando a importância de ambientes heterogêneos que promovam a aprendizagem de todos os alunos. (Política Nacional de Educação Especial na Perspectiva da Educação Inclusiva, janeiro de 2008).

A vista do exposto acima, podemos perceber que se faz de fundamental importância que a escola venha a criar situações de aprendizagem que atenda a todos sem distinção ou exclusão.

Sabemos da indispensabilidade de se estreitar os laços da família com a escola a fim de melhorar cada vez mais o processo de inclusão e aprendizagem. À vista disto, é inegável a importância da escola está sempre solicitando a participação ativa da família no âmbito escolar já que a inclusão deve acontecer em todas as esferas da sociedade e não somente na escola, sendo assim, a família dever ser a primeira a promover a inclusão já que a mesma é o primeiro grupo social ao qual pertencemos. Pois, [...] estudar exclusão pelas emoções dos que a vivem é refletir sobre o 'cuidado' 
que o Estado tem com seus cidadãos (Sawaia,2002:99). Diante disso, afirmação à essencialidade de se fazer um trabalho com a participação ativa da família no âmbito escolar.

\section{Desta forma quanto a Educação}

Inclusiva a Declaração de Salamanca conforme seu próprio texto (UNESCO, Ministry of Education and Spain, 1994) deixa registrado que:

(...) Inclusão e participação são essenciais à dignidade humana e ao gozo e exercício dos direitos humanos. No campo da educação, tal se reflete no desenvolvimento de estratégias que procuram proporcionar uma equalização genuína de oportunidades. A experiência em muitos países demonstra que a integração de crianças e jovens com necessidades educacionais especiais é mais eficazmente alcançada em escolas inclusivas que servem a todas as crianças de uma comunidade. (p.61)

Contudo, fica explicito qual grandiosa e importante e faz a inclusão na vida dos educandos com NEE como também dos demais, pois no espaço onde a diversidade é aceita e respeitada todos saem ganhando já que todos terão a oportunidade de conviver com o “diferente" já que quando aceitamos e respeitamos as diferenças passamos a adquirir conhecimentos nunca antes imaginados, pois todos independente das limitações que possuam tem muito a ensinar.

Sendo assim, uma classe que convive diariamente com diferenças acentuadas é um espaço propicio para se aprender a respeitar, a valorizar e a ser solidários, pois já não é aceitável que se descrimine ou exclua agora o essencial no âmbito escolar e a valorização da diversidade.

A vista disto a Declaração de Salamanca claro que:

O princípio fundamental da escola inclusiva é o de que todas as crianças deveriam aprender juntas, independentemente de quaisquer dificuldades ou diferenças que possam ter. As escolas inclusivas devem reconhecer e responder às diversas necessidades de seus alunos, acomodando tanto estilos como ritmos diferentes de aprendizagem e assegurando uma educação de qualidade a todos através de currículo apropriado, modificações organizacionais, estratégias de ensino, uso de recursos e parceiras com a comunidade (...) Dentro das escolas inclusivas, as crianças com necessidades educacionais especiais deveriam receber qualquer apoio extra que possam precisar, para que se lhes assegure uma educação efetiva (...) (op.cit., p.61)

Sendo assim, é preciso que todos entendam que toda criança e adolescente tem direito de mante-se, adquirir conhecimentos e intervir na escola como também na sociedade. Toda via, fica evidente que todo educando independente de sua deficiência tem o direito de receber atendimento nas escolas regulares sejam elas públicas ou privadas através do AEE (Atendimento Educacional Especializado).

Assim,

As iniciativas em favor do acesso dos alunos da educação especial às turmas das escolas comuns e aos novos serviços especializados propostos pela Política de 2008 visam à transposição das barreiras que os impediam de cursar com autonomia todos os níveis de ensino em suas etapas e modalidades, resguardado o direito à diferença, na igualdade de direitos. (MANTOAN, 2011). 
Entretanto, tendo como princípio um seguimento educacional que procura incluir e ocupa-se de servir crianças e adolescentes com NEE na escola regular se torna essencialmente fundamental que se tenha profissionais qualificados para trabalhar de forma eficiente e satisfatória atendendo esse público com o respeito e a dignidade que os mesmos merecem, pois não basta receber esses educandos se faz necessário que os mesmos tenham de fato um atendimento de qualidades para que assim possa acontecer uma aprendizagem significativa.

\section{Portanto,}

Esse lugar não é abstrato, mas um espaço, denominado Sala de Recursos Multifuncionais, que reúne recursos humanos e materiais que envolvem novos conhecimentos, equipamentos, arranjos e parcerias e uma gestão da presença da educação especial na escola, que está sendo pouco a pouco sentida e considerada pela comunidade escolar e pelos pais a partir de novas práticas de encaminhamento, estudos e planos de ação educativos. (MANTOAN, 2011).

Sendo que, além de recursos de qualidade se faz essencial à garantia de recursos pedagógico e pessoal de apoio como também o apoio da família e da comunidade escolar como um todo.

\section{3- CONCLUSÃO}

A conclusão deste trabalho se dar diante da certeza que as crianças e adolescentes com Necessidades Educacionais Especiais (NEE) devem e tem o direito garantido por lei ao acesso a uma educação de qualidade de fato.

Pois, já não basta que seu acesso à escola seja garantindo por lei é preciso que a mesma venha a permanecer no âmbito escolar com sua participação ativa para que assim de fato venham a ocorrer uma educação inclusiva fazendo com que esses educandos tenham direito a educação e a cidadania tanto quanto os outros educandos que não venham a apresentar nenhuma NEE.

Desta forma, o envolvimento familiar na escola como nos demais processos educacionais das crianças e adolescentes com NEE se faz indispensável já à família é o primeiro grupo social ao qual pertencemos sendo este importantíssimo na busca e aquisição do saber.

Diante disto, a parceria família escola tem muito a contribuir para uma educação inclusiva de qualidade já que, os vínculos estabelecidos entre a escola e a família traz um impacto positivo diante da aprendizagem dos jovens com NEE.

Sendo assim, a escola precisa conhecer a realidade de seus educandos fora do âmbito escolar e isso acontece quanto se busca a parceria da família fazendo assim com que os professores conheçam de fato seu alunado e o meio parental no qual o mesmo encontrasse inserido. 
Portanto ao termino deste artigo

temos a certeza de que quando de fato acontece a parceria família- escola ocorre uma educação inclusiva de qualidade já que essa é a parceria que faz a diferença na vida de nossos educandos, sendo assim devemos este sempre buscando trabalhar juntos para que aconteça uma educação significativa de qualidade.

\section{REFERÊNCIAS}

BRASIL. Constituição da República Federativa do Brasil. Brasília: Imprensa Oficial, 1988.

BRASIL. Ministério da Educação. Secretaria da Educação Especial. Política Nacional de Educação Especial, na perspectiva da Educação Inclusiva. Brasília:MEC/SEESP, 2008.

BRASIL. Decreto no. 3.956, de 8 de outubro de 2001. Promulga a Convenção Interamericana Para a Eliminação de Todas as Formas de Discriminação Contra as Pessoas Portadoras de Deficiência. Guatemala: 2001.

ORGANIZAÇÃO DAS NAÇÕES UNIDAS. Convenção sobre os direitos das pessoas com Deficiência, 2006.

SANTOS, Boaventura de Souza. Um discurso sobre as ciências. São Paulo: Cortez Editores, 2006.

MANTOAN, M.T. Eglér. Diferenciar para incluir: a educação especial na perspectiva da educação inclusiva 22/09/2011.

http://diversa.org.br/artigos/artigos.php?id= 42\&/diferenciar_para_incluir_a_educacao_ especial_na_perspectiva_da_educacao_incl usiva acesso em 23/07/15. 